\title{
High fish oil diet promotes liver inflammation and activates the complement system
}

\author{
HUIMIN JIN ${ }^{1,2}$, CHENG YAN ${ }^{1,3}$, TENGFEI XIAO ${ }^{1,3}$, NANNAN YAN ${ }^{1,3}$, JIE XU $^{1,3}$, LIPING ZHOU ${ }^{4}$, \\ XIAOMING ZHOU ${ }^{5}$, QIXIANG SHAO ${ }^{1,3}$ and SHENG XIA ${ }^{1,3}$ \\ ${ }^{1}$ Department of Immunology, School of Medicine, Jiangsu University, Zhenjiang, Jiangsu 212013; \\ ${ }^{2}$ Department of Experimental Medicine, Nanjing Drum Tower Hospital, Nanjing University Medical School, \\ Nanjing, Jiangsu 210008; ${ }^{3}$ Institute of Clinic Laboratory Diagnostic; Departments of ${ }^{4}$ Molecular Biology and \\ ${ }^{5}$ Pathology, School of Medicine, Jiangsu University, Zhenjiang, Jiangsu 212013, P.R. China
}

Received September 21, 2017; Accepted February 28, 2018

DOI: $10.3892 / \mathrm{mmr} .2018 .8687$

\begin{abstract}
Diets rich in $n-3$ polyunsaturated fatty acid (n-3 PUFA) fish oil (FO) have beneficial effects in obesity-associated metabolic disease. However, contradictory roles in inflammatory disease intervention have been reported. Our previous work revealed that a high-FO diet promoted myeloid cell differentiation by modifying the bone marrow microenvironment; however, its effects on liver inflammation and complement system activation remain unknown. By performing ELISA, reverse transcription-quantitative polymerase chain reaction, flow cytometry and histology on mice fed with high-FO and low-fat diets, the present study demonstrated that a 4 -week high-FO diet promoted liver inflammation in mice without affecting body or liver weight. The livers of high-FO diet mice exhibited increased infiltration of $\mathrm{T}$ cells and CD11b+ Gr-1+ myeloid cells. Additionally, a higher level of IL-1 $\beta$ and MCP-1 mRNA expression was detected, suggesting that the high-FO diet promoted liver inflammation. Further experiments indicated that the high-FO diet increased the total hemolytic complement activity (CH50), promoted the production of the membrane attack complex and increased the levels of various complement proteins in vivo, including complement components $\mathrm{C} 3, \mathrm{C} 4 \mathrm{~b}, \mathrm{Clqb}$ and factor B. Furthermore, higher concentrations of triglyceride were detected in the peripheral blood of high-FO diet mice, indicating the potential protective roles of n-3 PUFAs in FO against lipotoxicity in hyperlipidemia. Collectively, the present study demonstrated that high FO intake induced inflammation and activated the complement system in the liver. However, further study is required to determine the exact mechanisms.
\end{abstract}

Correspondence to: Dr Sheng Xia, Department of Immunology, School of Medicine, Jiangsu University, 301 Xuefu Road, Zhenjiang, Jiangsu 212013, P.R. China

E-mail: xiasheng1519@163.com

Key words: fish oil, inflammation, complement, liver

\section{Introduction}

The immune system defends against the high number of non-self antigens, including pathogens that threaten host viability (1). To achieve this, it uses a remarkable array of immune processes that enable the efficient recognition, initiation and elimination of harmful antigens to maintain biological homeostasis (2). The immune response depends on antigen-specific recognition and is typically classified into innate and adaptive components, which are mediated by $\mathrm{T}$ and B lymphocytes, and innate immune cells, respectively (3). There is synergy between these two arms of immunity, mediated by immune components that involve several different proteins and mediators, including cytokines and the complement system (4).

The complement system is comprised of $>30$ proteins in the plasma and cell membrane, organized through a hierarchy of proteolytic cascades that are triggered by initiators (5). Following activation, complement system components assemble the membrane attack complex (MAC) to form pores in the cell membrane to destroy target cells. During complement activation, several potent pro-inflammatory mediators, including complement proteins $\mathrm{C} 3 \mathrm{a}$ and C5a, are simultaneously generated. These mediators further induce anaphylaxis, recruit infiltrating inflammatory immune cells and regulate $\mathrm{T}$ cell function $(6,7)$. It has also been reported that complement activation has a role in reducing necrotic cell-induced inflammation by clearing dying cells and thereby aiding in the prevention of autoimmune diseases $(8,9)$. Recently, Suresh et al $(10)$ demonstrated that MAC formation can result in NACHT, LRR and PYD domains containing protein 3 (NLRP3) inflammasome activation, which in turn activates caspase-1 and promotes secretion of the inflammatory cytokines interleukin (IL)- $1 \beta$ and IL-18. Thus, complement activation can affect inflammation through multiple mechanisms.

In recent decades, the association between lipid metabolism and inflammation or immunity has been widely explored. Cumulative studies have revealed that a typically western diet rich in saturated fatty acids and n- 6 polyunsaturated fatty acids (n-6 PUFAs) induces obesity and causes immune cell 
infiltration into adipose tissue $(11,12)$. Thus, dietary fatty acids can act as pro-inflammatory factors, promoting low-grade chronic inflammation and insulin resistance in obesity (13-15). Complement activation may have a key role in these high-fat diet-induced metabolic diseases (16). Mice deficient in $\mathrm{C} 1$ activation or treated with $\mathrm{C} 1$ or $\mathrm{C} 2$ receptor antagonists have reduced inflammatory cytokine production and are protected from high-fat diet-induced metabolic dysfunction $(17,18)$. Bavia et al (19) demonstrated that C5 contributes to liver steatosis and inflammation in the pathogenesis of non-alcoholic liver disease. These data demonstrate the interplay between dietary fatty acids and the complement system.

In contrast to saturated and n-6 PUFAs, n-3 PUFAs, which are prevalent in fish oil (FO), are known to have beneficial anti-inflammatory effects and can attenuate obesity-associated diseases through various molecular mechanisms $(20,21)$. Although published studies suggest contradictory roles of dietary FO in inflammatory disease intervention, the role of FO in the function and development of immune cells has been confirmed $(22,23)$. High FO intake can affect lymphocytes and promote myeloid cell differentiation by modifying the bone marrow microenvironment (23). However, the precise mechanism of FO in the complement system remains unknown. In the present study, mice were fed a high FO diet in order to determine the effect of high dietary FO on complement activation and inflammation in the liver. The results indicated that a high FO diet may promote inflammation and complement activation in the liver.

\section{Materials and methods}

Animals. C57BL/6 mice were purchased from the laboratory animal facility of Yangzhou University (Yangzhou, China) and bred in a specific-pathogen-free facility. As described in our previous work (24), 10 6-week-old male C57BL/6 mice $(25 \mathrm{~g})$ were fed a low-fat-diet (LFD; Teklad 2914; Harlan Teklad Research Diets, Inc., Madison, WI, USA) or a high-FO diet (59\% fat, FO diet, D01112604; Research Diets, Inc., New Brunswick, NJ, USA) for 4 weeks prior to experimentation ( $\mathrm{n}=5$ each group). The mice were sacrificed using carbon dioxide (air displacement rate, 15\%/min) and tissues were subsequently collected. Body, liver and spleen weight were recorded. All protocols were approved by the Scientific Investigation Board of Jiangsu University (Zhenjiang, China).

Preparation of single-cell suspensions from mesenteric lymph nodes (MLNs) and spleens. MLNs and spleens were collected, cut into small pieces and incubated in RPMI-1640 medium (PAA Laboratories; GE Healthcare Life Sciences, Little Chalfont, UK) containing $10 \%$ fetal bovine serum (FBS; PAA Laboratories; GE Healthcare Life Sciences), PBS and collagenase IV (5 mg/ml; Invitrogen; Thermo Fisher Scientific, Inc., Waltham, MA, USA) with constant agitation for $20 \mathrm{~min}$ at $37^{\circ} \mathrm{C}$. The tissues were washed in PBS and subsequently homogenized by pipetting to produce a single-cell suspension. Cells were passed through a steel mesh filter prior to centrifugation at $51 \mathrm{x} \mathrm{g}$ for $5 \mathrm{~min}$ at $4^{\circ} \mathrm{C}$ and re-suspension in PBS. For splenocyte preparation, red blood cells were destroyed using an ammonium-chloride-potassium lysis buffer (eBioscience;
Thermo Fisher Scientific, Inc.) according to the manufacturer's protocols.

Non-parenchymal cell (NPCs) purification. Liver NPCs were prepared as previously described, with minor modifications (25). Livers collected from high-FO or LFD mice were cut into small pieces and incubated in RPMI-1640 medium containing $10 \% \mathrm{FBS}, \mathrm{PBS}$ and collagenase IV ( $5 \mathrm{mg} / \mathrm{ml}$; Invitrogen; Thermo Fisher Scientific, Inc.) with constant shaking for $20 \mathrm{~min}$ at $37^{\circ} \mathrm{C}$. The tissues were washed in $\mathrm{PBS}$, homogenized by pipetting to produce a single-cell suspension and were passed through a steel mesh filter prior to centrifugation at $51 \mathrm{x} \mathrm{g}$ for $5 \mathrm{~min}$ at $4^{\circ} \mathrm{C}$. Cells were resuspended in $40 \%$ Percoll (GE Healthcare, Chicago, IL, USA) and subsequently added to $70 \%$ Percoll. The NPCs were further purified by density centrifugation at $321 \mathrm{x}$ g for $20 \mathrm{~min}$ at $4{ }^{\circ} \mathrm{C}$. Cells from the buffy coat layer between the 70 and $40 \%$ Percoll were collected and washed with PBS.

ELISA. Blood samples were collected from the anesthetized mice by cardiac puncture. Serum was prepared by spontaneous coagulation followed by centrifugation at $900 \mathrm{x} \mathrm{g}$ for $20 \mathrm{~min}$ at $4^{\circ} \mathrm{C}$. The serum was stored at $-80^{\circ} \mathrm{C}$ and multiple freeze/thaw cycles were avoided. Total hemolytic complement activity [50\% total hemolytic complement activity (CH50; cat. no.ml001989)], MAC (cat.no.ml002054), C3 (cat.no.ml002033) and triglyceride (TG) (cat. no. ml037783) serum levels were quantified by ELISA (Shanghai Enzyme-linked Biotechnology Co., Ltd., Shanghai, China; http://www.mlbio.cn/) according to the manufacturer's protocols.

Reverse transcription-quantitative polymerase chain reaction (RT-qPCR) analysis. Liver tissues were harvested, snap-frozen in liquid nitrogen, and stored at $-80^{\circ} \mathrm{C}$ for further experimentation. The tissue was homogenized in TRIzol reagent (Thermo Fisher Scientific, Inc.) using a tissue homogenizer and total RNA was prepared according to the manufacturer's protocols. cDNA was synthesized using SuperScript ${ }^{\mathrm{TM}}$ III First-Strand Synthesis System (cat. no. 18080051; Invitrogen; Thermo Fisher Scientific, Inc.). qPCR was performed using SYBR Premix Ex Taq II ${ }^{\mathrm{TM}}$ (cat. no. RR820; Takara Biotechnology Co., Ltd., Dalian, China) and Bio-Rad (Bio-Rad Laboratories, Inc., Hercules, CA, USA) equipment according to the manufacturer' protocols. Generally, qPCR cycling was performed using the following amplification conditions: $95^{\circ} \mathrm{C}$ for $30 \mathrm{sec}$, followed by 40 cycles of $95^{\circ} \mathrm{C}$ for $15 \mathrm{sec}, 60^{\circ} \mathrm{C}$ for $20 \mathrm{sec}$, and $72^{\circ} \mathrm{C}$ for $30 \mathrm{sec}$. The relative mRNA levels of the target genes were normalized to $\beta$-actin (26) (Table I).

Flow cytometry. Cell suspensions were incubated with rat serum (cat. no. 10710C; 1:50; Invitrogen; Thermo Fisher Scientific, Inc.) at $4^{\circ} \mathrm{C}$ for $10 \mathrm{~min}$ to prevent non-specific binding and were subsequently stained with the following fluorescein-labeled antibodies $(1: 200)$ at $4^{\circ} \mathrm{C}$ for $20 \mathrm{~min}$ : Anti-T-cell surface glycoprotein CD3 (CD3; cat. no. 11-0032), anti-T-cell surface glycoprotein CD4 (CD4; cat. no. 12-0043), anti-T-cell surface glycoprotein CD8 (CD8; cat. no. 15-0081), anti-lymphocyte antigen 6 complex locus G (Gr-1; cat. no. 25-5931), anti-integrin $\alpha \mathrm{M}$ (CD11b; cat. no. 11-0112) and anti-receptor-type tyrosine-protein phosphatase C (CD45; cat. 
Table I. Primers used for reverse transcription-quantitative polymerase chain reaction analysis.

\begin{tabular}{ll}
\hline Gene & \multicolumn{1}{c}{ Sequence (5'-3') } \\
\hline C3 & F: TGGTGGAGAAAGCAGTGATG \\
& R: ACGGGCAGTAGGTTGTTGC \\
C4b & F: CAGGACAGAACAGTGGAGCA \\
& R: CCCAAAGGAGCCATCATTC \\
C1qb & F: CAACCTGTGTGTGAATCTCGTT \\
& R: GGTGAACAACCTCCTCTTGC \\
Factor B & F: AAGTGTCAAGAAGGTGGCTCA \\
& R: TCAGGGAGGATAGGAATGCTT \\
Factor H & F: ACCTCGCTGTGTTGGACTTC \\
& R: CCACTTTCCTCCTTCGCATA \\
MASP1 & F: GCAAGGAGAGGGAAGATGAAG \\
& R: CCTGTTGTCTGTGTGGAGGA \\
IL-1 $\beta$ & F: TGTGAAATGCCACCTTTTGA \\
& R: TGAGTGATACTGCCTGCCTG \\
MCP-1 & F: ATGCAGGTCCCTGTCATG \\
$\beta$-actin & R: GCTTGAGGTGGTTGTGGA \\
& F: TGGAATCCTGTGGCATCCATGAAAC \\
& R:TAAAACGCAGCTCAGTAACAGTCCG
\end{tabular}

C3, complement component 3; C4b, complement component 4b; $\mathrm{C} 1 \mathrm{qb}$, complement component $1 \mathrm{q}$ subcomponent $\beta$ polypeptide; MASP1, mannan-binding lectin serine peptidase 1 ; IL-1 $\beta$, interleukin $1 \beta$; MCP-1, C-C motif chemokine 2.

no. 12-0451) All antibodies were purchased from eBioscience (Thermo Fisher Scientific, Inc.). Cell samples were washed with PBS three times prior to assessment by flow cytometry (FACSCalibur; BD Biosciences, Franklin Lakes, NJ, USA). Data were analyzed using CellQuest software (version 6.1, BD Biosciences) or FlowJo (version 8.7, FlowJo LLC, Ashland, OR, USA).

Histology. Liver samples were harvested, fixed in $4 \%$ buffered formalin at room temperature overnight, dehydrated and embedded in paraffin (27). Cross sections (5 $\mu$ m thick) were stained with hematoxylin and eosin according to the protocol (cat. no. 60524ES60; Yeasen Co., Ltd., Shanghai, China) and observed under a light microscope (Axio Observer; Zeiss AG, Oberkochen, Germany). Images were acquired using AxioVision software (version 4.8.2, Zeiss AG). All images were captured at magnification, $\mathrm{x} 400$.

Statistical analysis. The data were statistically analyzed by a two-tailed Student's t-test using GraphPad (version 7.0, GraphPad Software, Inc., La Jolla, CA, USA) and are presented as the mean \pm standard error. Experiments were repeated three times. $\mathrm{P}<0.05$ was considered to indicate a statistically significant difference.

\section{Results}

General evaluation of mice fed high-FO diet. To investigate the effects of a FO on C57BL/6 mice, male mice were fed a high-FO diet for 4 weeks (Fig. 1A). For each diet group, body, liver and spleen weight was recorded. As we previously reported (25), the FO diet had no obvious effect on body weight (Fig. 1B); however, the spleen weight and size were markedly increased in the FO group (Fig. 1C). There was no significant difference in the liver weight (Fig. 1D) or the liver/body weight ratio (Fig. 1E). Although there was no difference in liver weight between the LFD-fed and FO-fed mice, liver congestion was observed in the FO-fed cohort by visual inspection (Fig. 1D). Similarly, changes were observed in the secondary lymphoid organs of the gut (Fig. 1F). Compared to MLNs retrieved from the LFD cohort, which had a pearly white, smooth and transparent surface, the MLNs of FO-fed mice were greasier, more adhesive and light yellow in color (Fig. 1F). TG serum concentration of mice fed high-FO or LFD diets were determined. As presented in Fig. 1G, the FO-diet significantly increased the concentration of TG compared with LFD mice. These results indicated that the high-FO diet may affect lipid metabolism and impair peripheral immune organ homeostasis, including the liver, spleen and MLNs.

High-FO diet induces liver inflammation. As the liver has important roles in immunity and metabolism, the effects of the FO diet on the liver were evaluated. NPCs were isolated and various immune cell populations were analyzed by flow cytometry. The percentage of CD4+ T cells and $\mathrm{CD} 8+\mathrm{T}$ cells among the total population of $\mathrm{CD} 3+\mathrm{T}$ cells was determined. The percentage of CD8+ $\mathrm{T}$ cells in $\mathrm{CD} 3+$ cells was significantly decreased in the high-FO diet group compared with the LFD group (Fig. 2A and B). By contrast, the percentage of CD4+ T cells in CD3+ cells significantly increased in the high-FO diet group compared with the LFD group (Fig. 2A and B).

Gr-1+ myeloid cells are comprised of Gr-1-high neutrophils $\left(\mathrm{CD} 11 \mathrm{~b}+\mathrm{Gr}-1^{\text {hi }}\right)$ and $\mathrm{Gr}-1$-moderate monocytes $(\mathrm{CD} 11 \mathrm{~b}+$ Gr- $1^{\text {int }}$ (28). The results revealed that $\mathrm{CD} 11 \mathrm{~b}+\mathrm{Gr}-1^{\mathrm{hi}}$ and $\mathrm{CD} 11 \mathrm{~b}+\mathrm{Gr}-1^{\text {int }}$ myeloid cell populations were significantly increased in the livers of the high-FO diet group compared with the LFD group (Fig. 2C and D), indicating that more inflammatory immune cells infiltrated the liver following FO consumption, although no significant difference was observed by histological examination (Fig. 2E). Pro-inflammatory cytokine profiles in liver tissues were subsequently assessed. IL-1 $\beta$ and $\mathrm{C}-\mathrm{C}$ motif chemokine 2 (MCP-1) mRNA expression in the liver tissues of the high-FO diet mice was significantly higher than those in the LFD group (Fig. 2F). Collectively, these data demonstrated that the FO diet induced liver inflammation.

High-FO diet feeding promotes complement system activation. As the liver is one of the major organs involved in complement protein production, and complement activation is tightly associated with inflammation and immunity (29), the effects of the high-FO diet on the complement system were examined. CH50 and levels of MAC in the serum were determined. Significantly higher CH50 (Fig. 3A) and MAC (Fig. 3B) production was detected in the serum of high-FO diet mice. C3 is the most prevalent protein in the complement system and is involved in all complement activation pathways (30). ELISA and RT-qPCR analyses demonstrated that the levels of C3 protein in the serum (Fig. 3C) and mRNA in the liver tissues 

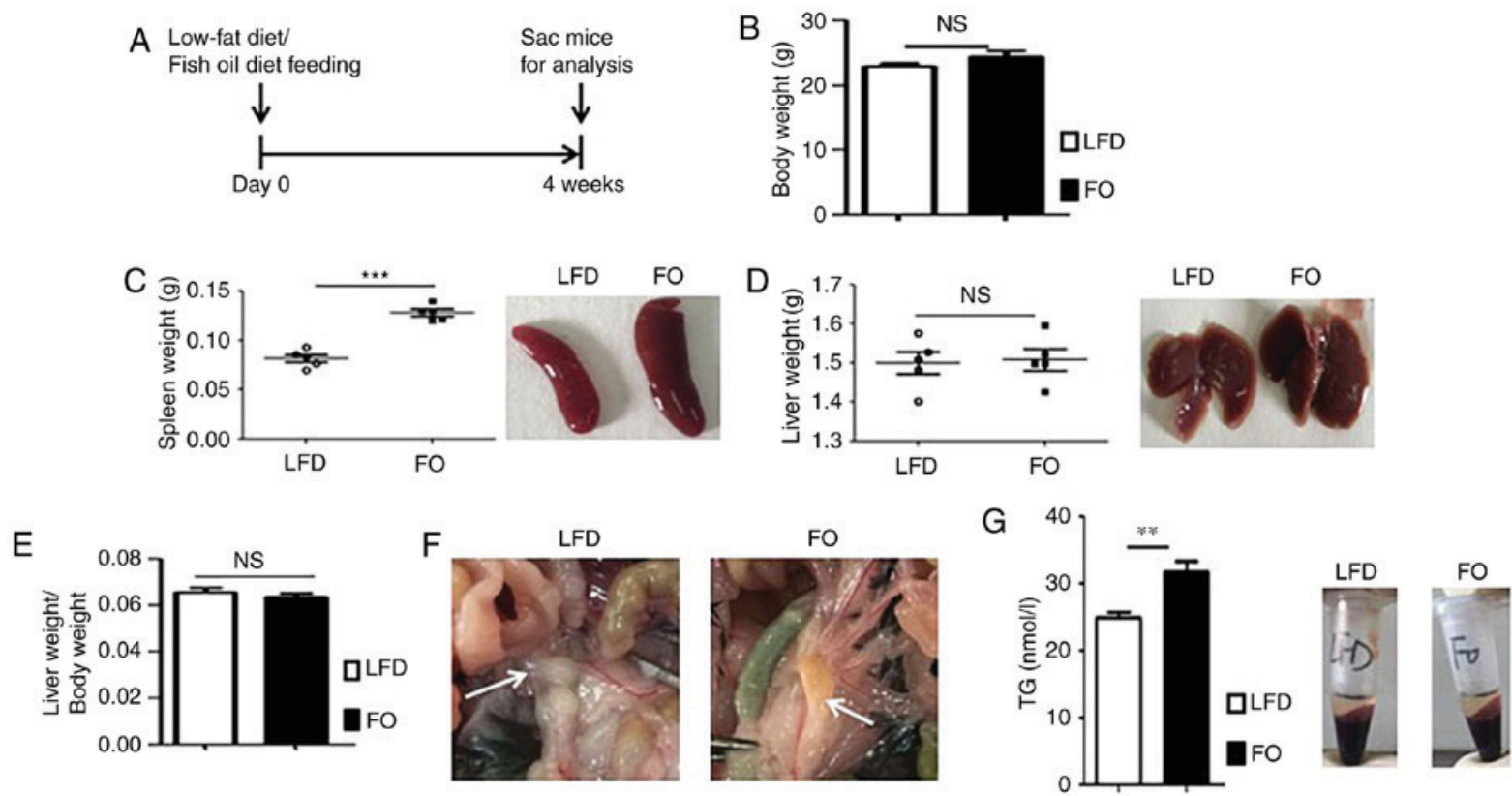

Figure 1. General evaluation of C57BL/6 mice fed a high-FO diet. (A) Mice were fed either a LFD or high-FO diet for 4 weeks Mice were subsequently euthanized for the analysis of (B) body weight, (C) spleen weight (D) liver weight and (E) liver/body weight ratio. (F) Observable structure of the mesenteric lymph nodes. (G) Blood samples were collected from mice to prepare serum and TG levels in the serum were analyzed by ELISA. The data are representative of three independent experiments. $\mathrm{n}=5$ per group. The data are presented as the mean \pm standard error. ${ }^{*} \mathrm{P}<0.05,{ }^{* * *} \mathrm{P}<0.01,{ }^{* * *} \mathrm{P}<0.001$ vs. LFD group. NS, no significance; FO, fish oil; LFD, low fat diet; TG, triglyceride.

A

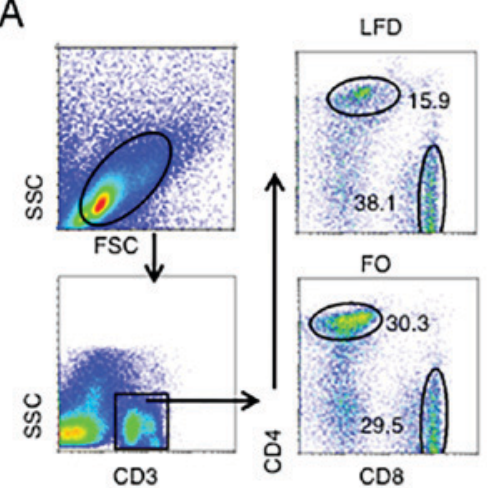

C

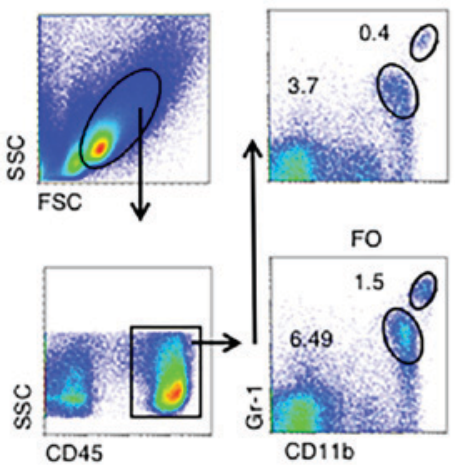

B

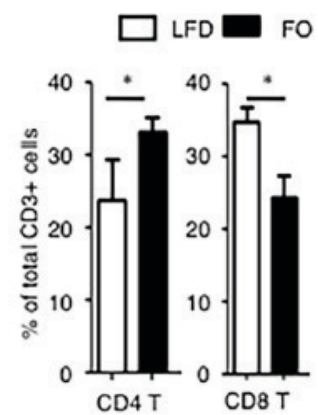

D

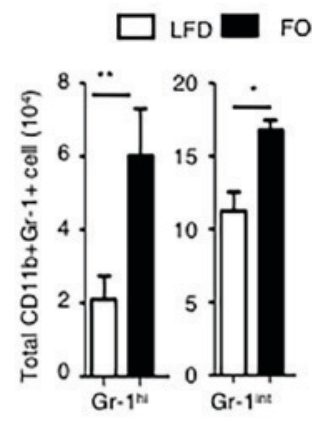

$\mathrm{E}$

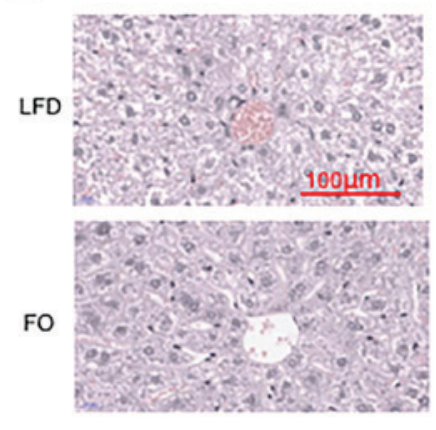

$\mathrm{F}$

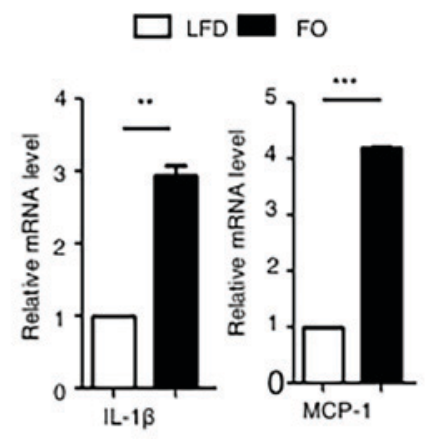

Figure 2. A high-FO diet induces liver inflammation. Livers from LFD or high-FO diet mice were collected for analysis of immune cell populations, the inflammatory cytokine profile and histology. Nonparenchymal hepatic cells were prepared from liver tissue and the percentage of (A) number of CD4+ or CD8+ T cells among the CD3+ cells was analyzed by flow cytometry and (B) the cell percentage calculated. (C) Number of Gr-1+cells among the CD45+ cells was analyzed using flow cytometry and (D) the cell percentage was calculated. (E) Representative image of liver histology following hematoxylin and eosin staining. (F) IL-1 $\beta$ and MCP-1 mRNA expression in liver tissue was determined by reverse transcription-quantitative polymerase chain reaction. The data are representative of three independent experiments and are presented as the mean \pm standard error. $\mathrm{n}=5$ per group. ${ }^{*} \mathrm{P}<0.05,{ }^{* * *} \mathrm{P}<0.01,{ }^{* * * *} \mathrm{P}<0.001$. SSC, side scatter; FSC, forward scatter; CD3, T-cell surface glycoprotein CD3; CD4, T-cell surface glycoprotein CD4; CD8, T-cell surface glycoprotein CD8; LFD, low fat diet; FO, fish oil; CD45, receptor-type tyrosine-protein phosphatase C; CD11b, integrin $\alpha$ M; Gr-1, lymphocyte antigen 6 complex locus G; CD11b+ Gr-1 ${ }^{\text {hi }}$, Gr-1-high neutrophils; CD11b+ Gr-1 ${ }^{\text {int }}$, Gr-1-moderate monocytes; IL-1 $\beta$, interleukin 1 $\beta$; MCP-1, C-C motif chemokine 2. 

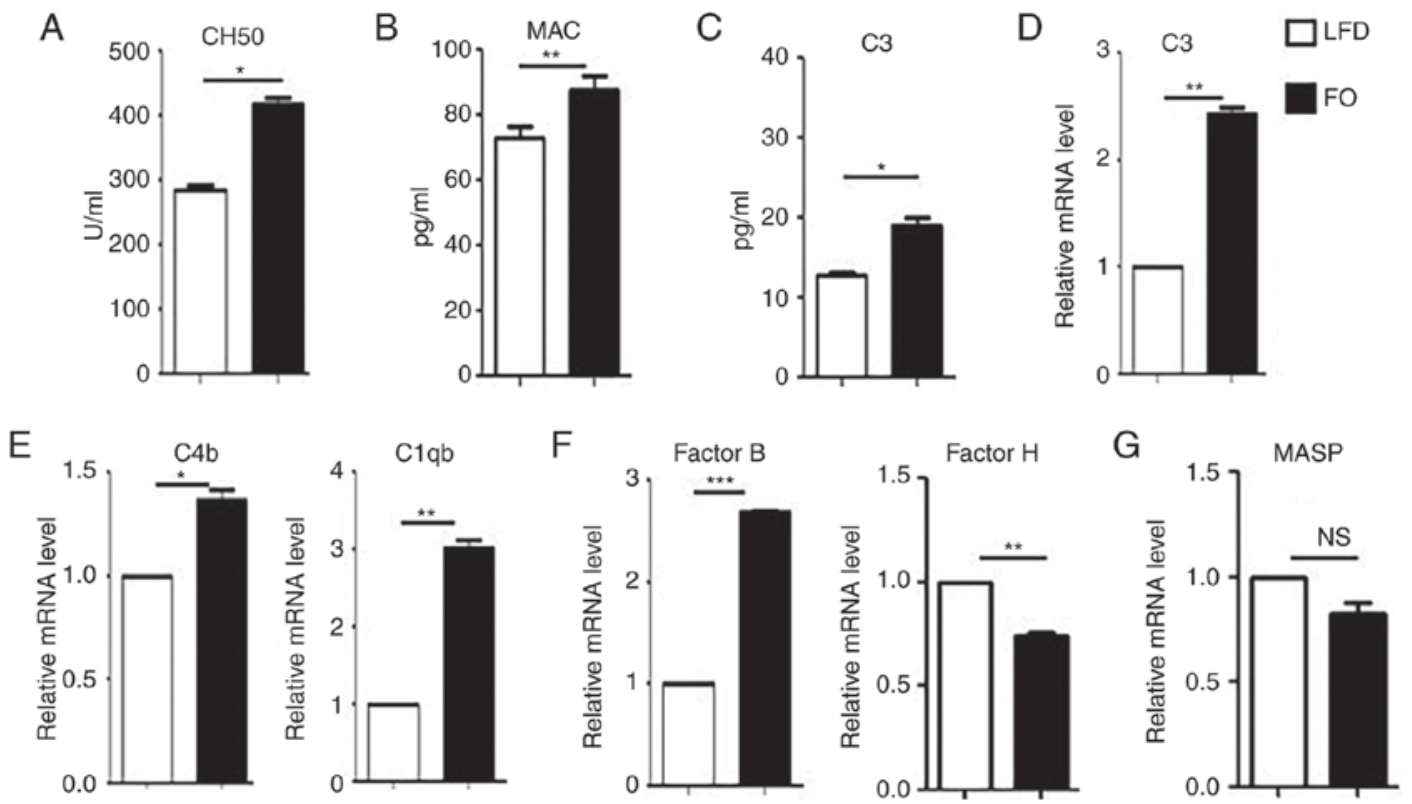

Figure 3. A high-FO diet promotes complement system activation. Serum and liver tissues were collected from LFD and high-FO diet mice. (A) CH50 and (B) the levels of MAC in the serum samples were detected using ELISA. (C) The protein levels of C3 in the serum and (D) mRNA levels of C3 in the liver tissue were analyzed by ELISA and RT-qPCR, respectively. The mRNA levels in the liver of (E) complement proteins C4b and Clqb in the classical pathway, (F) factor B and factor $\mathrm{H}$ in the alternative pathway and (G) MASP1 in the lectin pathway were determined using RT-qPCR. The relative mRNA levels of different target genes were normalized to $\beta$-actin. The data are representative of three independent experiments and are presented as the mean \pm standard error. $\mathrm{n}=5$ per group. ${ }^{*} \mathrm{P}<0.05,{ }^{* *} \mathrm{P}<0.01,{ }^{* * * *} \mathrm{P}<0.001$ vs. LFD group. RT-qPCR; reverse transcription-quantitative polymerase chain reaction; $\mathrm{CH} 50,50 \%$ total hemolytic complement activity; MAC, membrane attack complex; C3, complement C3; FO, fish oil; LFD, low fat diet; C4b, complement component C4b; C1qb, complement component 1 q subcomponent $\beta$ polypeptide; MASP1, mannan-binding lectin serine peptidase 1; NS, no significance.

(Fig. 3D) were significantly increased in the high-FO diet group, compared with the LFD group. Additionally, the mRNA expression of $\mathrm{C} 4 \mathrm{~b}$ and $\mathrm{C}$ 1qb (Fig. 3E), two other important activation components in the classical complement activation pathway, were significantly increased in the liver of the high-FO diet group, compared with the LFD group. The effects of the high-FO diet on other pathways of the complement system were also investigated. Significantly increased mRNA expression of complement factor $\mathrm{B}$, one component of the alternative pathway, was detected in the liver (Fig. 3F). Additionally, complement factor $\mathrm{H}$, an inhibitory complement regulatory protein in the alternative pathway, was significantly reduced in the high-FO diet group compared with the LFD group (Fig. 3F). There was no significant difference in the mRNA level of mannan-binding lectin serine peptidase 1 (MASP1), a specific component of the lectin pathway (Fig. 3G). Taken together, these findings indicate that a high-FO diet may promote complement activation.

\section{Discussion}

Our previous study demonstrated that a high-FO diet promoted myeloid-derived suppressor cell differentiation, suppressed T-cell-mediated adaptive immunity and promoted tumor growth through multiple mechanisms, including the alteration of hematopoiesis and the bone marrow microenvironment (24). However, the effects of a high-FO diet on the complement system, a key effector and regulator of innate and adaptive immunity, are not clear. The present study provided evidence of complement activation and inflammation in the liver tissue of mice fed a high-FO diet. After 4 weeks on a high-FO diet, increased levels of CH50 and MAC were detected in the serum, indicating that the FO diet increased complement activation in vivo.

The liver is a unique organ that has important roles in both the digestive and immune systems. In our previous study, it was demonstrated that a saturated fatty acid and n-6 PUFA-rich high-fat diet induced low-degree inflammation in the liver (24). Nevertheless, in the current study, an n-3 PUFA-rich FO diet promoted the infiltration of CD11b+ Gr-1+ inflammatory myeloid cells into the liver, suggesting that the induction of liver inflammation is mediated specifically by n-3 PUFA-rich feeding, rather than by fatty acids and n-6 PUFAs. We previously reported that $\mathrm{FO}$ feeding modified bone marrow hematopoiesis and induced splenomegaly in mice (25). In the present study, a high-FO diet not only increased the weight of the spleen, but also increased the number of $\mathrm{Gr}-1+$ myeloid cells in the liver. Considering the similar roles of the spleen and liver in extramedullary hematopoiesis, the increased myeloid cell infiltration into the liver was likely closely associated with the effects of FO on bone marrow hematopoiesis. Higher levels of MCP-1 in the liver may have also contributed.

The liver contains specialized resident immune cells and is also the predominant site of complement protein biosynthesis. Although previous studies have demonstrated that most mammalian cell types are capable of producing some or all of the complement proteins (31), these extrahepatic complement proteins are synthesized in a tissue-specific manner and have biological functions predominantly within the local environment (32). By contrast, systemic complement proteins are synthesized in the liver by hepatocytes $(33,34)$. A previous study demonstrated that complement proteins C1q, C7 and factor D are predominantly synthesized in extrahepatic 
sites (31). However, the liver is the main source of the major complement protein $\mathrm{C} 3$, although monocyte/macrophage lineage cells also contribute to extrahepatic C3 production. In the present study, increased protein and mRNA levels of $\mathrm{C} 3$ were detected in the serum and liver tissue, respectively. Considering the source and the role of $\mathrm{C} 3$ in the complement system, these data suggest that the high-FO diet induced increased liver cell synthesis of $\mathrm{C} 3$, which has the potential to upregulate the biological effects of the complement system.

The function of the complement system depends on the activation of an array of complement components, which subsequently organize a hierarchy of proteolytic cascades. Based on their differing initiation factors and complement components, three different complement activation pathways have been identified; the classical, alternative and lectin pathways (35). All pathways use the assembled MAC to create a pore that mediates cytotoxicity in the target cell. In the present study, increased levels of MAC were detected in the serum of the high-FO diet mice, indicating that complement activation had increased. In the classical pathway, following initiation by immune complexes, $\mathrm{Clq}$ forms a complex with subcomponents $\mathrm{C} 1 \mathrm{r}$ and $\mathrm{C} 1 \mathrm{~s}$ to form serine proteases, which cleave $\mathrm{C} 4$ into large $\mathrm{C} 4 \mathrm{~b}$ and small $\mathrm{C} 4 \mathrm{a}$ fragments. In the present study, the mRNA levels of $\mathrm{C} 1 \mathrm{qb}$ and $\mathrm{C} 4 \mathrm{~b}$ were increased in the high-FO diet mice, suggesting that the high-FO diet promoted activation of the classical complement pathway. This finding was further confirmed by the $\mathrm{CH} 50$ analysis, in which increased $\mathrm{CH} 50$ was detected in the high-FO group, compared with the LFD group. The high-FO diet-induced activation of the classical complement pathway may be initiated by $\mathrm{C} 1 \mathrm{q}$ recognition of modified lipids in vivo (36). Factor B interacts with C3 to activate the alternative complement pathway, which is negatively regulated by factor $\mathrm{H}$. The present study demonstrated that factor B mRNA expression was increased, and the mRNA expression of negative regulatory protein factor $\mathrm{H}$ was reduced in the liver of high-FO diet mice, indicating that the alternative pathway was activated. The association between the complement system, metabolism and inflammasome activation has been extensively research. Anaphylatoxins C3a and C5a, products of complement activation, have been confirmed as important drivers of NLRP3 activation, through induction of IL-1 $\beta$ gene transcription in monocytes (37-39). Consistent with these findings, high mRNA levels of IL-1 $\beta$ were detected in the liver of FO-fed mice in the present study, indicating that IL-1 $\beta$ may be involved in high-FO diet-mediated complement activation. The data of the present study is consistent with the findings of previous studies $(18,40)$ that demonstrated that complement activation is closely associated with lipid metabolism in the liver and contributes to liver homeostasis and disease.

TG is the storage form of excess free fatty acids. Generally, adipose tissues have the capacity to store excess free fatty acids as TGs in lipid droplets; however, excess lipid accumulation in non-adipose tissues can cause cell death or dysfunction, which is termed lipotoxicity. It has been demonstrated that unsaturated fatty acids have protective roles against lipotoxicity in hyperlipidemic states through promoting TG accumulation (41). Compared with the LFD group, the high-FO diet group in the present study was fed a variety of n-3 PUFAs, including eicosapentaenoic acid, docosapentaenoic acid and docosahexaenoic acid. Unfortunately, this FO diet also contained more saturated fatty acids and n-6 PUFAs than the LFD, including palmitic acid (PA) and myristic acid (MA). The concentration of $\mathrm{PA}$ and MA in the high-FO diet was 24.3 and $51.9 \mathrm{~g} / \mathrm{kg}$, respectively, but these saturated fatty acids were at very low concentrations in the LFD (25). Thus, the high TG level in the serum following FO feeding largely depended on the higher intake of saturated fatty acids. Similarly, previous work demonstrated that excess saturated fatty acids and n-6 PUFAs in the diet induced complement activation and contributes to obesity-associated metabolic diseases (16). Thus, although the exact mechanism of the effects of a high-FO diet in the activation of complement and liver inflammation was not been clearly demonstrated in this study, saturated fatty acids and n-6 PUFAs in a high FO diet may partly contribute. In addition, the exact role and potential mechanisms of n-3 PUFAs in the activation of complement and liver inflammation should be further explored using purified DHA and PEA. As fish oil is currently been used in the prevention and therapy of cardiovascular diseases, the side effects of the high-FO diet in complement activation need to be avoided in this treatment.

\section{Acknowledgements}

The authors are very thankful to all members of the Zhou laboratory and the Shao laboratory for helpful discussion.

\section{Funding}

The present study was funded by grants from the National Natural Science Foundation of China (grant nos. 31570879, 31428006 and 81172834) and the Jiangsu Provincial Key Research and Development Program (grant no. BE2017696).

\section{Availability of data and materials}

The analyzed datasets generated during the study are available from the corresponding author on reasonable request.

\section{Author's contributions}

SX designed experiment, interpreted the data and drafted the manuscript. HJ performed the majority of the experiments and was a major contributor in writing the manuscript. CY, TX and JX performed animal models preparation and flow cytometer analysis. LZ and NY performed ELISA. XZ and QS analyzed and interpreted the data and revised the manuscript. All authors read and approved the final manuscript.

\section{Ethics approval and consent to participate}

All protocols were approved by the Scientific Investigation Board of Jiangsu University (Zhenjiang, China).

\section{Consent for publication}

Not applicable. 


\section{Competing interests}

The authors declare that they have no competing interests.

\section{References}

1. Banchereau J and Steinman RM: Dendritic cells and the control of immunity. Nature 392: 245-252, 1998.

2. Austyn JM: Death, destruction, danger and dendritic cells. Nat Med 5: 1232-1233, 1999.

3. Iwasaki A and Medzhitov R: Regulation of adaptive immunity by the innate immune system. Science 327: 291-295, 2010.

4. Cruvinel Wde M, Mesquita D Jr, Araújo JA, Catelan TT, de Souza AW, da Silva NP and Andrade LE: Immune system-part I. Fundamentals of innate immunity with emphasis on molecular and cellular mechanisms of inflammatory response. Rev Bras Reumatol 50: 434-461, 2010 (In English, Portuguese).

5. Walport MJ: Complement. First of two parts. N Engl J Med 344: 1058-1066, 2001

6. Arbore G, West EE, Spolski R, Robertson AAB, Klos A, Rheinheimer C, Dutow P, Woodruff TM, Yu ZX, O'Neill LA, et al: $\mathrm{T}$ helper 1 immunity requires complement-driven NLRP3 inflammasome activity in $\mathrm{CD}^{+} \mathrm{T}$ cells. Science 352 : aad1210, 2016.

7. Cravedi P, van der Touw W and Heeger PS: Complement regulation of T-cell alloimmunity. Semin Nephrol 33: 565-574, 2013.

8. Martin M and Blom AM: Complement in removal of the dead-balancing inflammation. Immunol Rev 274: 218-232, 2016.

9. Ricklin D, Hajishengallis G, Yang $\mathrm{K}$ and Lambris JD: Complement: A key system for immune surveillance and homeostasis. Nat Immunol 11: 785-797, 2010.

10. Suresh R, Chandrasekaran P, Sutterwala FS and Mosser DM: Complement-mediated 'bystander' damage initiates host NLRP3 inflammasome activation. J Cell Sci 129: 1928-1939, 2016.

11. Liu HQ, Qiu Y, Mu Y, Zhang XJ,Liu L, Hou XH, Zhang L, Xu XN Ji AL, Cao R, et al: A high ratio of dietary n-3/n- 6 polyunsaturated fatty acids improves obesity-linked inflammation and insulin resistance through suppressing activation of TLR4 in SD rats. Nutr Res 33: 849-858, 2013.

12. Serini S, Piccioni E, Merendino N and Calviello G: Dietary polyunsaturated fatty acids as inducers of apoptosis: Implications for cancer. Apoptosis 14: 135-152, 2009.

13. Shoelson SE, Lee J and Goldfine AB: Inflammation and insulin resistance. J Clin Invest 116: 1793-1801, 2006.

14. Kalupahana NS, Claycombe KJ and Moustaid-Moussa N: (n-3) Fatty acids alleviate adipose tissue inflammation and insulin resistance: Mechanistic insights. Adv Nutr 2: 304-316, 2011.

15. Cooke AA, Connaughton RM, Lyons CL, McMorrow AM and Roche HM: Fatty acids and chronic low grade inflammation associated with obesity and the metabolic syndrome. Eur J Pharmacol 785: 207-214, 2016.

16. Vlaicu SI, Tatomir A, Boodhoo D, Vesa S, Mircea PA and Rus H: The role of complement system in adipose tissue-related inflammation. Immunol Res 64: 653-664, 2016.

17. Lim J, Iyer A, Suen JY, Seow V, Reid RC, Brown L and Fairlie DP: $\mathrm{C} 5 \mathrm{aR}$ and $\mathrm{C} 3 \mathrm{aR}$ antagonists each inhibit diet-induced obesity, metabolic dysfunction and adipocyte and macrophage signaling. FASEB J 27: 822-831, 2013.

18. Hillian AD, McMullen MR, Sebastian BM, Roychowdhury S, Kashyap SR, Schauer PR, Kirwan JP, Feldstein AE and Nagy LE: Mice lacking $\mathrm{C} 1 \mathrm{q}$ are protected from high fat diet-induced hepatic insulin resistance and impaired glucose homeostasis. J Biol Chem 288: 22565-22575, 2013.

19. Bavia L, Cogliati B, Dettoni JB, Ferreira Alves VA and Isaac L: The complement component $\mathrm{C} 5$ promotes liver steatosis and inflammation in murine non-alcoholic liver disease model. Immunol Lett 177: 53-61, 2016.

20. Alvarez-Curto E and Milligan G: Metabolism meets immunity: The role of free fatty acid receptors in the immune system. Biochem Pharmacol 114: 3-13, 2016.
21. Viggiano E, Mollica MP, Lionetti L, Cavaliere G, Trinchese G, De Filippo C, Chieffi S, Gaita M, Barletta A, De Luca B, et al: Effects of an high-fat diet enriched in lard or in fish oil on the hypothalamic amp-activated protein kinase and inflammatory mediators. Front Cell Neurosci 10: 150, 2016

22. Poreba M, Mostowik M, Siniarski A, Golebiowska-Wiatrak R, Malinowski KP, Haberka M, Konduracka E, Nessler J, Undas A and Gajos G: Treatment with high-dose n-3 PUFAs has no effect on platelet function, coagulation, metabolic status or inflammation in patients with atherosclerosis and type 2 diabetes. Cardiovasc Diabetol 16: 50, 2017.

23. Kremer JM: Fish oil and inflammation-A fresh look. J Rheumatol 44: 713-716, 2017.

24. Xia S, Li X, Cheng L, Han M, Zhang M, Liu X, Xu H, Zhang M, Shao Q and Qi L: Chronic intake of high fish oil diet induces myeloid-derived suppressor cells to promote tumor growth. Cancer Immunol Immunother 63: 663-673, 2014.

25. Xia S, Li XP, Cheng L, Han MT, Zhang MM, Shao QX, Xu HX and Qi L: Fish oil-rich diet promotes hematopoiesis and alters hematopoietic niche. Endocrinology 156: 2821-2830, 2015.

26. Livak KJ and Schmittgen TD: Analysis of relative gene expression data using real-time quantitative PCR and the 2(-Delta Delta $\mathrm{C}(\mathrm{T}))$ method. Methods 25: 402-408, 2001.

27. Xia S, Guo Z, Xu X, Yi H, Wang Q and Cao X: Hepatic microenvironment programs hematopoietic progenitor differentiation into regulatory dendritic cells, maintaining liver tolerance. Blood 112: 3175-3185, 2008.

28. Xia S, Sha H, Yang L, Ji Y, Ostrand-Rosenberg S and Qi L: Gr-1+ $\mathrm{CD} 11 \mathrm{~b}+$ myeloid-derived suppressor cells suppress inflammation and promote insulin sensitivity in obesity. J Biol Chem 286: 23591-23599, 2011.

29. Gao B, Jeong WI and Tian Z: Liver: An organ with predominan innate immunity. Hepatology 47: 729-736, 2008

30. Ricklin D, Reis ES, Mastellos DC, Gros P and Lambris JD: Complement component C3-The 'Swiss Army Knife' of innate immunity and host defense. Immunol Rev 274: 33-58, 2016.

31. Morgan BP and Gasque P: Extrahepatic complement biosynthesis: Where, when and why? Clin Exp Immunol 107: 1-7, 1997.

32. Marsh JE, Zhou W and Sacks SH: Local tissue complement synthesis-fine tuning a blunt instrument. Arch Immunol Ther Exp (Warsz) 49 (Suppl 1): S41-S46, 2001.

33. Alper CA, Johnson AM, Birtch AG and Moore FD: Human C'3: Evidence for the liver as the primary site of synthesis. Science 163: 286-288, 1969

34. Morris KM, Aden DP, Knowles BB and Colten HR: Complement biosynthesis by the human hepatoma-derived cell line HepG2. J Clin Invest 70: 906-913, 1982.

35. Walport MJ: Complement. Second of two parts. N Engl J Med 344: 1140-1144, 2001

36. Arlaud GJ, Biro A and Ling WL: Enzymatically modified low-density lipoprotein is recognized by clq and activates the classical complement pathway. J Lipids 2011: 376092, 2011.

37. Arbore G and Kemper C: A novel 'complement-metabolism-i nflammasome axis' as a key regulator of immune cell effector function. Eur J Immunol 46: 1563-1573, 2016.

38. SamstadEO, Niyonzima N,NymoS, Aune MH, Ryan L, Bakke SS, Lappegård KT, Brekke OL, Lambris JD, Damås JK, et al: Cholesterol crystals induce complement-dependent inflammasome activation and cytokine release. J Immunol 192: 2837-2845, 2014.

39. Haeffner-Cavaillon N, Cavaillon JM, Laude $M$ and Kazatchkine MD: C3a(C3adesArg) induces production and release of interleukin 1 by cultured human monocytes. J Immunol 139: 794-799, 1987.

40. Bavia L, de Castro IA, Cogliati B, Dettoni JB, Alves VA and Isaac L: Complement C5 controls liver lipid profile, promotes liver homeostasis and inflammation in C57BL/6 genetic background. Immunobiology 221: 822-832, 2016.

41. Listenberger LL, Han X, Lewis SE, Cases S, Farese RV Jr, Ory DS and Schaffer JE: Triglyceride accumulation protects against fatty acid-induced lipotoxicity. Proc Natl Acad Sci USA 100: 3077-3082, 2003. 